\title{
95 后大学生的性观念现状调查研究一一工科院校的学生为例
}

\author{
张由月 \\ 成都工业学院 \\ DOI:10.32629/er.v3i7.2941
}

\begin{abstract}
[摘 要] 随着社会的快速发展,95后大学生的性观念也会随之发生变化,笔者以工科院校的学生为例, 对 95后大学生的性观念、性行为进行调查研究。从国家、学校、家庭等方面加强性教育, 对于维护性心理 健康,形成良好的大学生性文明,有着非常重要的现实意义。
\end{abstract}

[关键词] 95后; 大学生; 性观念; 调查

性是什么? 是权利还是义务? 是生 殖需要还是快乐源泉? 当代大学生该怎 样正确地面对性困惑? 要回答以上问题 最根本在于: 形成健康、正确的性观念。 所谓性观念是指个体或群体对性的内在 标准的总的认识和看法。如: 恋爱观、 贞操观、性现象观、婚前性行为观、性 爱观等。

\section{1 问题提出}

国内外学者大量的实证研究丰富了 有关大学生性观念的资料, 也为本文提 供了丰富的参考资料。但这些研究基本 上都是针对 80 后、 90 后的大学生的性观 念调查, 专门针对 95 后大学生的相关调 查研究尚未见到。

随着社会的快速发展, 人们的性观 念也会随之发生改变。当代的大学生基 本上都是 95 后, 95后大学生有他们自己 独特的时代文化背景和心理特征。加之 工科院校的男女比例严重失调, 男男同 性性行为的现象呈上升态势。

因此, 笔者以工科院校的学生为例, 对95后大学生的性观念进行调查研究。 对于了解大学生性观念的真实动态, 有 针对性的开展性心理健康维护工作; 传 播科学的性知识, 积极推动大学生艾滋 病的防控教育; 引导他们树立健康的性 观念, 形成良好的大学生性文明, 有着非 常重要的现实意义。

\section{2 调查研究}

2.1对象

本研究以四川省工科院校的大学生
为研究对象, 选取了其中三所大学的在 读大学生共 2512 名, 层次分别为 211 大学, 普通本科、和专科学校随机抽取不同年 级和专业的学生为调查对象, 其中大二 学生652名, 大三学生916名, 大四学生 932名, 均为 95 后大学生。收回有效问卷 2380 份, 回收率 $95 \%$, 其中男生占比率为 $71 \%$, 女生为 $29 \%$ 。

\section{2 方法}

拟采用文献查阅与问卷调查等方式 收集, 从个体的总体性观念评价、接受性 教育方式、贞操观、婚前性行为观、性 爱观等维度进行调查研究, 并对初级资 料进行整理分析。为该研究提供有效数 据和相关理论依据。以便获得更为真实 和丰富的资料。

\section{3 调查结果分析}

2. 3. 接受性教育情况分析

调查结果显示, 大学生接受性教育 的途径依次是: 学校组织的生理课占50\%, 各种网站浏览获取的占 $24 \%$, 父母家庭教 育占 $12 \%$, 观看电影电视, 书籍, 报刊杂志 等占 $14 \%$ 。

根据调查数据显示, 大学生获得性 教育的主渠道是学校开设的相关性教育 课程。这个途径正规, 有利于大学生形成 良好稳定的性观念。另外, 家长们也越来 越重视对孩子的性教育了。相比以前的 家长在性教育方面总是避而不谈的情况, 部分95后大学生的父母已经开始试着给 孩子创造一个良好的性教育环境, 这是 社会进步的表现。
数据显示, $92 \%$ 的大学生认为性教育 对性观念的影响程度是很大的。他们希 望通过高校获得性教育知识的需求是很 强烈的, 自身也有从学校、家庭等途径获 得性知识的主观意识。

\section{3. 2 对待婚前性行为的态度}

当代大学生对爱与性的关系的理解 和对性活动的接受程度直接影响着对待 婚前性行为的态度, 是大学生形成性观 念的重要表现。调查显示, 在看待爱与性 的关系上, $54 \%$ 的同学认为性必须是要以 爱为基础; $22 \%$ 的同学认为爱与性同等重 要, 可以同时产生。认为必须有爱, 可以 无性有 $8 \%$; 认为爱必须要以性为基础的 占 $8 \%$; 认为必须有性, 可以无爱占 $6 \%$ 。这 说明绝大多数大学生认同性不能脱离爱, 爱比性更重要的观点。

对待婚前性行为的态度, $70 \%$ 的同学 认为婚前性行为是合理的。这部分同学 认为, 随着社会观念的开放, 大部分大学 生认为在安全的前提下适当满足性心理 需求是可以接受的, 是合理的。人们的性 观念也越来越开放, 尤其是对那些认真 严肃, 以结婚为目的爱情关系中的性行 为表现出更多的理解与包容。

\subsection{3性困惑情况分析}

性困惑是指对性生理变化缺乏必要 的心理准备而产生的不适现象, 是性意 识觉醒的一种表现。性压抑是青春期普 遍存在的一种性心理现象。适当的性压 抑是合理的, 是人类文明进步的表现。

在对大学生性幻想的调查中显 
示, $26 \%$ 的人没有出现过性梦或性幻想; $54 \%$ 的人表示他们偶尔会出现性幻想; $8 \%$ 的人承认他们经常会有性幻想, 并受到 性压抑的痛苦; $50 \%$ 的人会通过转移注意 力的方式来处理自己的性冲动; $8 \%$ 的人 会压抑自己的性冲动; $4 \%$ 的人会通过发 生性行为来缓解性冲动; $24 \%$ 的人会通过 性自慰的方式来寻求自我满足。适度自 慰可以释放得不到正常生理满足的压抑 感, 调节紧张情绪, 但过度则会影响人的 身心健康。

\subsection{4贞操观分析}

贞操观是大学生性观念的一个重要 表现, 随着当代大学生性观念的逐渐开 放, 贞操观有弱化的趋势。调查显示, $70 \%$ 的人比较能接受自己的男 (女) 朋友不是 处男 (女); $12 \%$ 的人完全不能接受自己的 男 (女) 朋友不是处男 (女)。在对待婚前 贞洁是否应该男女都遵守的态度上, 有 $40 \%$ 的人认为是男女都应该遵守; $4 \%$ 的人 认为是女性应该遵守, 男性无所谓; $10 \%$ 的人认为男女都可以不遵守婚前贞洁; $30 \%$ 的人觉得无所谓。这些数据表明当代 大学生的性观念发生了很大的变化, 同 时又面临着处理性与爱, 传统性观念与 当代性观念的一些冲突与困惑。

总体来讲, 大学生认为自己的性观 念比较开放的占 $35 \%$, 比较传统有 $25 \%$, 居 于中间程度的占 $35 \%$ 。随着时代的变化， 大学生的性观念也发生了很多变化, 呈 现出多元化、包容性的特点。因此, 通过 数据调查, 分析了解大学生的性观念情 况, 有利于从社会、学校、家庭、个体多 方面做工作, 帮助学生形成正确健康文 明的性观念。

\section{3 建议与对策}

性观念对大学生的性价值取向和性 行为有着重要的作用。帮助当代大学生 形成科学的性观念, 提高性心理健康水 平已成为家庭、学校、社会不可忽视的 问题。
3. 1增强家庭对性教育的重视程度

性的发展与人的发展一样, 从出生 到幼儿, 从童年到少年, 从青年到老年。 在人的不同成长时期, 人的性心理发展 与特点是不一样的, 需要完成的阶段性 任务也不同。早期的性教育问题都需要 父母或共同生活的成年人来帮助完成。

因此, 作为一个当代父母, 首先自己 要树立良好的性观念, 不断学习科学的 性知识, 再对孩子进行性教育引导。孩子 的性心理会随着生理变化, 从幼年时期 喜欢问的 “我从哪里来” 的问题到青年 初期对性的好奇等这些都是人的性心理 发展的必然规律和正常现象。性研究发 现, 任何一个成年人的性问题都能在孩 童时期找到踪迹。家长从认知上改变, 坦然面对孩子的性问题, 与孩子建立平 等开放的对话机制, 以便孩子在成长过 程中遇到性困惑能及时寻求家长帮助, 得到正确引导。所以, 家长科学、正确的 性观念将会影响到孩子的性道德和性行 为, 良好的家庭性教育有利于孩子形成 科学的性观念。

3.2 从教育部到学校逐级完善性教 育方式

此次调查数据显示, $90 \%$ 的学生认 为在大学生中开展性健康教育很有必 要, 学生希望通过高校获得性教育知识 的需求是很强烈的。他们希望更多的是 通过学校开设性健康教育的必修课、选 修课已及相关讲座的等方式来获得系 统的性知识。近几年来, 学校里不断出 现的学生以及老师的性道德、性犯罪以 及艾滋病传播等问题不容忽视。这些现 象都表明了我国在性教育方面存在一 定的缺失。

因此, 教育部应将性健康教育纳入 必修课程体系, 重视教师的性知识专业 技能培养, 完善性教育课程体系, 以帮助 学校开设适合学生需求的综合的、积极 立体的课程。同时, 学校要将性教育课程
体系落到实处, 根据学生身心发展规律 建立从幼儿园到小学、中学到大学的系 列课程, 以帮助学生树立科学、健康的性 观念。

3. 3建立性和谐社会

人是社会的人, 社会环境对大学生 性观念的影响是很大的。调查发现, 有部 分大学生是通过网络影视、报刊杂志等 社会渠道来获取性知识的。因此, 政府应 采取相应的措施净化环境, 正确导向大 众传媒, 抵制不良信息, 拒绝 “黄色鸦 片”; 健全相关制度, 普及性知识, 传播性 文化的正能量, 提高大众对性的正确认 知。一方面, 加大对社会大众的正面性观 念意识的宣传力度; 另一方面, 进行积极 的性行为干预, 严厉打击淫秽信息传播、 卖淫强奸等性犯罪行为。为培养大学生 的性道德责任感营造健康、文明、积极 的社会氛围, 以帮助大学生建立科学、健 康的性观念, 构建性和谐社会。

\section{课题项目:}

本文系四川性社会学与性教育研究 中心课题 “95后大学生的性观念现状调 查研究一以工科院校的学生为例”的研 究成果。

\section{[参考文献]}

[1]胡珍.大学生性观念发展趋势研 究[J].青少年研究,2014,(5):43-47.

[2]王进金金.当代青少年的性爱观考 察[J].中国青年研究,2012,(5):90-95.

[3]程静.当前青少年婚前性行为现 状及影响因素实证研究[J].中国青年研 究,2015,(5):54-58.

[4]方静.90后在校大学生性观念现状 调查[J].中国性科学,2015,25(4):151-155.

\section{作者简介：}

张由月(1982--), 女, 汉族, 四川万源 人,讲师,硕士研究生, 成都工业学院学工 部心理咨询中心,研究方向: 大学生心理 健康教育。 